\title{
Awareness Regarding Oral Aphthous Ulcers and its Risk Factors Among BDS and MBBS Students-A Cross-Sectional Survey
}

\author{
Marium Azfar ${ }^{1}$ \\ Saima Qureshi \\ Syeda Noureen Iqbal ${ }^{3}$ \\ Sadia Rizwan ${ }^{4}$ \\ Imran Khan \\ Arfa Baig ${ }^{6}$ \\ Khadijah Abid ${ }^{7}$
}

\author{
BDS, MPH \\ BDS, FCPS \\ BDS, FCPS \\ BDS, FCPS \\ BDS, MSc \\ BDS, FCPS
}

MSPH, MSc, BS Hons

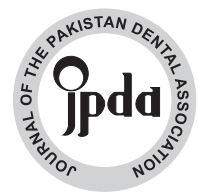

OBJECTIVE: The objective of this paper was to assess the awareness regarding oral aphthous ulcers and its risk factors among BDS and MBBS students in private institute of Karachi, Pakistan.

METHODOLOGY: A cross-sectional survey was conducted at a private institute of Karachi Pakistan for the duration of six months. Medical and dental students of age more than 18 years of either gender were enrolled in the study using non-probability convenience sampling technique. Pre-designed proforma was used to collect data regarding demographics, history of recurrent aphthous stomatitis and knowledge of oral aphthous ulcers and its risk factors. The knowledge score of 4 out of 6 was considered as adequate knowledge. SPSS version 25 was used to analyze data.

RESULTS: Of 150 participants, the mean age was reported as 22.94 \pm 1.65 years (range: $21-25$ years). In those 150 participants 46 were males $(30.7 \%)$ and 104 were females $(69.3 \%)$. Overall mean score of knowledge was $4.35 \pm 1.29$. Wherein $73 \%$ had adequate knowledge regarding oral ulceration and its risk factors. The dental students had significantly higher proportion of adequate knowledge regarding oral ulceration than medical students [ $\mathrm{p}=0.024]$.

CONCLUSION: Overall students had good knowledge of oral ulceration and its risk factors, wherein knowledge of dental students was better than medical students.

KEYWORDS: Oral ulcers; Recurrent Aphthous stomatitis; awareness, oral ulceration, risk factors, eating habits HOW TO CITE: Azfar M, Qureshi S, Iqbal SN, Rizwan S, Khan I, Baig A, Abid K. Awareness regarding oral aphthous ulcers and its risk factors among BDS and MBBS students-A cross-sectional survey. J Pak Dent Assoc 2021;30(3):215-218.

DOI: https://doi.org/10.25301/JPDA.303.215

Received: 25 November 2020, Accepted: 25 May 2021

\section{INTRODUCTION}

$\mathrm{T}$ he most frequent type of ulcers occurring in the oral cavity are aphthous ulcers also known as recurrent aphthous stomatitis. It is a degradation

1. Associate Professor, Department of Community Dentistry, Sindh Institute of Oral Health Sciences.

2. Assistant Professor, Department of Operative Dentistry, Ziauddin Medical University

3. Assistant Professor, Department of Oral Surgery, Dow University of Health Sciences Ishrat Ul Ibad Khan Institute of Oral Health Sciences.

4. Assistant Professor, Department of Orthodontics, Dow University of Health Sciences.

5. Assistant Professor, Department of Community Dentistry, Sindh Institute of Oral Health Sciences.

6. Senior Registrar, Department of Oral Surgery Dow University of Health Sciences.

7. Lecturer, Department of Public Health, Szabist, Karachi.

Corresponding author: “Miss. Khadijah Abid” < khadijahabid@ gmail.com > of the epithelium that contributes to the formation of underlying inflamed conjunctive tissue. ${ }^{1}$ Almost $25 \%$ of people around the world suffer from oral ulcers and estimated point prevalence is $4 \%$ globally. ${ }^{2}$ It is prevalent among both genders but predominantly affects females and teenagers. ${ }^{3,4}$

Stress, family history, infective agents, allergic conditions, hormonal disturbances and gastrointestinal diseases are the most common etiological causes of oral ulceration, but the causes of recurrent aphthous stomatitis remain unknown and vague. ${ }^{1}$ However, literature showed that stress $(54.8 \%)$, was the common cause of recurrent aphthous stomatitis followed by nutritional deficiency as $25 \%$ (i.e. micro-nutrient deficiencies including iron, folate, zinc, B1, B2, B6, B12 deficiencies) and food stuff (16\%). ${ }^{2,5}$

Dental as well as medical graduates can play an 
important role in educating the patient, friends, families and communities regarding prevention, diagnosis and treatment of oral ulcers. ${ }^{6-8}$ Statistics regarding how well dental and medical students are aware of oral ulcers is unavailable. One research found that only $56 \%$ of dental students were familiar with the true etiology and therapies of oral ulcers and $64.2 \%$ of the dental students had experienced recurrent aphthous stomatitis which was prevalent among female students. ${ }^{9}$

There is lack of information available on the awareness of oral aphthous ulcers among medical and dental students in Pakistan. The purpose of the current study is therefore, to explore level of awareness among students. The study will help students learn about the disease diagnosis, its etiologies, therapies and prevention strategies.

\section{METHODOLOGY}

A cross-sectional survey was conducted at a private institute of Karachi Pakistan for the duration of six months. Sample size of 150 was estimated on Open epi sample size calculator using proportion of knowledge regarding true etiology and therapies of oral ulcers among dental students as 0.569 , absolute precision as $8 \%$ and $95 \%$ confidence level. Medical and dental students of age more than 18 years of either gender were enrolled in the study using non-probability convenience sampling technique. Participants who did not give consent were excluded from the study. This research was approved by ethical review committee of Sir Syed College of Medical Sciences (Ref\#SSCMS/College/Principal/Dental/20001161).

Study was initiated after taking verbal consent from all the eligible participants. Pre-designed proforma was used to collect data regarding demographics and history of recurrent aphthous stomatitis. Second section questionnaire included six questions regarding knowledge of oral aphthous ulcers and its risk factors. The knowledge score of 4 out of 6 was considered as adequate knowledge. The questionnaire for knowledge assessment was designed by the research team itself. The validation and reliability of the questionnaire was checked by applying reliability analysis which gave the value of Cronbach's alpha as $73 \%$.

SPSS version 25 was used to analyze data. Numeric data such as age and knowledge score were presented as mean and SD while categorical data like gender, education background, experience of oral ulcers knowledge questions and adequate knowledge was presented as frequency and percentage. Chi-square was applied to see the association between knowledge level and effect modifiers like age, gender, experience of oral ulcers and education background. A p-value $<0.05$ was taken as statistically significant.

\section{RESULTS}

Of 150 participants, the mean age was reported as $22.94 \pm 1.65$ years (range: $21-25$ years). Of 150 participants 46 were males $(30.7 \%)$ and 104 were females $(69.3 \%)$. Majority of the participants were dental students $(\mathrm{n}=81,54 \%)$ and 69 were medical students $(46 \%)$ respectively. Of 150 participants, 57 had experienced oral ulcers (38\%) and 93 had no experience (62\%).

About $88.7 \%$ of the participants claimed that they knew about oral ulcerations. Almost $71 \%$ said spicy food is risk factor for oral ulcers, $74 \%$ said smoking can cause oral ulcers and $69 \%$ considered stress as a risk factor. Of 150 participants $64 \%$ said family risk history is a risk factor for oral ulceration and $68.7 \%$ said type of toothpaste can play a role in occurrence of oral ulcerations. (Table 1)

Table 1: Assessment of awareness among students

\begin{tabular}{|l|l|l|}
\hline \multicolumn{1}{|c|}{ Items } & \multicolumn{1}{c|}{ No } & \multicolumn{1}{c|}{ Yes } \\
\hline Do you know about oral ulcers? & $17(11.3 \%)$ & $133(88.7 \%)$ \\
\hline Spicy food is a risk factor for oral ulcer & $43(28.7 \%)$ & $107(71.3 \%)$ \\
\hline Smoking can cause oral ulcer & $39(26 \%)$ & $111(74 \%)$ \\
\hline Stress can cause oral ulcer & $47(31.3 \%)$ & $103(68.7 \%)$ \\
\hline Family history is a risk factor for oral ulceration & $54(36 \%)$ & $96(64 \%)$ \\
\hline Type of tooth can play a role in oral ulceration & $47(31.3 \%)$ & $103(68.7 \%)$ \\
\hline
\end{tabular}

Of 150 participants, the overall mean score of knowledge was $3.87 \pm 1.13$. Wherein $67.3 \%$ had adequate knowledge regarding oral ulceration and its risk factors where $32.7 \%$ had inadequate knowledge. (Fig 1)

Fig 1: Frequency distribution of adequate knowledge

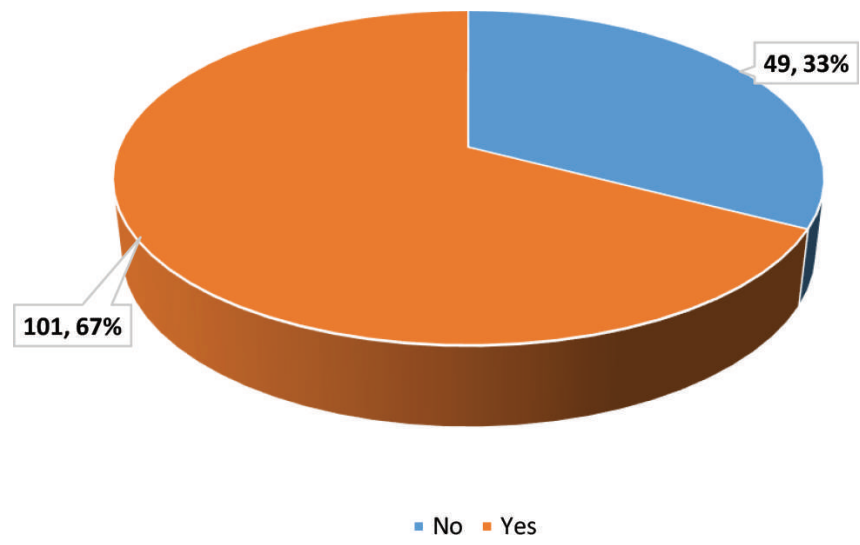

There was statistically insignificant difference in proportions of adequate knowledge with respect to age $(p=0.247)$, gender $(p=0.262)$, and experience of oral ulcerations $(\mathrm{p}=0.194)$. The dental students had significantly higher proportion of adequate knowledge regarding oral ulceration than medical students $[\mathrm{p}=0.024]$. (Table 2) 
Azfar M/ Qureshi S/ Iqbal SN/ Rizwan S/ Khan I/ Baig A/ Abid K

Table 2: Comparison of knowledge and potential factors

\begin{tabular}{|c|c|c|c|}
\hline \multirow[t]{2}{*}{ Variables } & \multicolumn{2}{|c|}{ Knowledge } & \multirow[t]{2}{*}{ p-value } \\
\hline & Inadequate & Adequate & \\
\hline \multicolumn{4}{|l|}{ Age groups } \\
\hline$>23$ years & $24(37.5 \%)$ & $40(62.5 \%)$ & \multirow[t]{2}{*}{0.276} \\
\hline$<=23$ years & $25(29.1 \%)$ & $61(70.9 \%)$ & \\
\hline \multicolumn{4}{|l|}{ Gender } \\
\hline Male & $18(39.1 \%)$ & $28(60.9 \%)$ & \multirow[t]{2}{*}{0.262} \\
\hline Female & $31(29.8 \%)$ & $73(70.2 \%)$ & \\
\hline \multicolumn{4}{|c|}{ Educational background } \\
\hline Medical student & $29(42 \%)$ & $40(58 \%)$ & \multirow[t]{2}{*}{$0.024^{*}$} \\
\hline Dental student & $20(24.7 \%)$ & $61(75.3 \%)$ & \\
\hline \multicolumn{4}{|c|}{ Experience of oral ulcerations } \\
\hline No & $34(36.6 \%)$ & $59(63.4 \%)$ & \multirow[t]{2}{*}{0.194} \\
\hline Yes & $15(26.3 \%)$ & $42(73.7 \%)$ & \\
\hline
\end{tabular}

\section{DISCUSSION}

A total of 150 students taken part in the study and responded back. Most of the participants were females and this reflects the dominancy of female students in medical and dental college. Out of 150 students. $88.7 \%$ of the students knew about oral ulcerations and $11.3 \%$ did not have idea of oral ulcerations. Similarly, in a previous research $85 \%$ of the responders knew about oral ulcerations. ${ }^{9}$ In a research by Rathod et al it was found that $44 \%$ of the students had history of oral ulceration. ${ }^{10}$ In our research, the experience of oral ulceration was low in all students (38\%). Whereas in previous researches, the experience of oral ulceration was high among all students. ${ }^{9,11,12}$

Some researches had showed that incidence of oral ulceration is highly correlated with diet. ${ }^{13,14}$ In previous researches of oral ulceration associated with diet have shown, that fried items and spicy foods are the potential risk factors for oral ulcers. ${ }^{15,16}$ thought that spicy food intake is the reason of oral ulcerations. ${ }^{9}$ In our research we found that $71.3 \%$ of the students knew that spicy food is a risk factor for oral ulcerations. This statistics highlights that Pakistani people usually consumes more spice in food on daily basis, and spicy food can influences the health outcomes like oral ulceration. ${ }^{17,18}$ Previous researches have also shown that stress and family history of risk factors of oral ulcerations. ${ }^{1,19}$ In current study, we found that most of the students knew that stress and positive family history of oral ulceration are risk factors of ulcerations. Hence, this is important for students to know which kind of food should be avoided and to manage stress in order to prevent ulceration. ${ }^{16}$

In our research, most students knew the form of toothpaste could cause oral ulceration (69 per cent). However, previous literature has demonstrated that students have limited
Awareness regarding oral aphthous ulcers and its risk factors among BDS and MBBS students-a cross-sectional survey

understanding of toothpaste ingredients. This can be troubling, since it is important to know the product you use to brush your teeth every day because whatever you consume, it should be safe enough. Herlofson et $\mathrm{al}^{20}$ has demonstrated that tooth paste containing sodium lauryl sulphate is one of the main cause of oral ulceration. In a similar research, it was revealed that $30 \%$ of the students did not know whether sodium lauryl sulphate is present in their toothpaste or not and $63.3 \%$ did not know about the chemical composition of the toothpaste. ${ }^{9}$ Another research reported that $72 \%$ of the students did not look at the chemical composition of toothpaste and they choose toothpaste on the basis of brand and price. ${ }^{21}$

The relationship between oral ulcerations and smoking is not fully cleared. However, the highest prevalence of oral ulcerations was observed among young individuals especially university students. ${ }^{22}$ A hospital based study also revealed that tobacco users had less chances of oral ulcerations as compared to non-users. ${ }^{23}$ The literature on the "protective effect" of tobacco use, particularly smoking, on aphthous ulceration has been heavily debated, especially in terms of a possible underlying mechanism. It's been suggested that smokers' oral mucosa has further keratinization. ${ }^{22}$ Keratinization prevents the oral tissues from bacterial penetration and trauma. Multiple compounds are ingested systemically from cigarette smoke, and one of these absorbed constituents that encourages keratinization may be hyperkeratosis, which is usually confined to the mucosal region where smokeless tobacco is kept. While hyperkeratosis is a premalignant disease, it is conceivable that it protects the oral mucosa from aphthous ulcers by providing a local protective impact. There is also debate about whether nicotine, which is found in cigarettes, or one of the tobacco product's constituents, causes the defensive effect. ${ }^{18,24}$ Nicotine is more systemically consumed in cigarettes than in nonsmokers, so the former may have a lower defensive benefit than the latter. ${ }^{18,24-26}$ In our study we found that $74 \%$ of the students thought that smoking can cause oral ulcerations. This shows that only $26 \%$ of participants had correct knowledge and were aware that smoking had protective effect on oral ulcerations.

In our study, most of the students were adequately aware of oral ulceration and its risk factors (67.3\%) and high proportion of knowledge regarding oral ulceration was observed among dental students. This study would be help in designing educational intervention for students mainly for final year students who are going to deal with patients.

\section{CONCLUSION}

Overall students had good knowledge of oral ulceration and its risk factors, wherein knowledge of dental students was better than medical students. 
Azfar M/ Qureshi S/ Iqbal SN/

Rizwan S/ Khan I/ Baig A/ Abid K

\section{CONFLICT OF INTEREST}

None to declare

\section{REFERENCES}

1. Minhas S, Sajjad A, Kashif M, Taj F, Waddani HA, Khurshid Z. Oral ulcers presentation in systemic diseases: An update. Open Access Maced J Med Sci. 2019;7:3341-347.

https://doi.org/10.3889/oamjms.2019.689

2. Patil S, Reddy SN, Maheshwari S, Khandelwal S, Shruthi D, Doni B. Prevalence of recurrent aphthous ulceration in the Indian Population. J Clin Exp Dent. 2014;6:e36-40.

https://doi.org/10.4317/jced.51227

3. Amadori F, Bardellini E, Conti G, Majorana A. Oral mucosal lesions in teenagers: a cross-sectional study. Ital J Pediatr. 2017;43:1-6. https://doi.org/10.1186/s13052-017-0367-7

4. Queiroz S, Silva M, Medeiros AMC, Oliveira PT, Gurgel BCV, Silveira É JDD. Recurrent aphthous ulceration: an epidemiological study of etiological factors, treatment and differential diagnosis. An Bras Dermatol. 2018;93:341-46.

https://doi.org/10.1590/abd1806-4841.20186228

5. Edgar NR, Saleh D, Miller RA. Recurrent aphthous stomatitis: A review. J Clin Aesthet Dermatol. 2017;10:26-36.

6. Ahamed S, Moyin S, Punathil S, Patil NA, Kale VT, Pawar G. Evaluation of the oral health knowledge, attitude and behavior of the preclinical and clinical dental students. J Int Oral Health. 2015;7:65-70.

7. Petrauskiene S, Mushayev H, Zemgulyte G, Narbutaite J. Oral health awareness among international dental and medical students at Lithuanian University of Health Sciences: a cross-sectional study. J Oral Maxillofac Res. 2019;10:e3.

https://doi.org/10.5037/jomr.2019.10403

8. Liu H-Y, Chen J-R, Hsiao S-Y, Huang S-T. Caregivers' oral health knowledge, attitude and behavior toward their children with disabilities. J Dent Sci. 2017;12:388-95.

https://doi.org/10.1016/j.jds.2017.05.003

9. C LP. Knowledge, experience and risk factors for oral aphthous ulcers among BDS students: University of Nairobi; 2009.

10. Rathod U, Kulkarni S, Agrawal V. Prevalence of recurrent aphthous ulcers in dental student: A questionnaire based study. Stress. 2017;180: 80-83.

11. Kaimenyi JT. Oral health in Kenya. Int Dent J. 2004;54:378-88. https://doi.org/10.1111/j.1875-595X.2004.tb00015.x

12. Kaimenyi J, Guthua S. Occurrence of ulcerative oral lesions at Kenyatta National Hospital, Nairobi, Kenya. Afr J Health Sci. 1994;1:179-81.

13. Du Q, Ni S, Fu Y, Liu S. Analysis of dietary related factors of recurrent aphthous stomatitis among college students. Evid Based Complement Alternat Med. 2018;2018:2907812.

https://doi.org/10.1155/2018/2907812
Awareness regarding oral aphthous ulcers and its risk factors among BDS and MBBS students-a cross-sectional survey

14. Challacombe SJ, Alsahaf S, Tappuni A. Recurrent aphthous stomatitis: Towards evidence-based treatment? Current Oral Health Reports. 2015;2:158-67.

https://doi.org/10.1007/s40496-015-0054-y

15. Ma R, Chen H, Zhou T, Chen X, Wang C, Chen Y, et al. Effect of bedtime on recurrent aphthous stomatitis in college students. Oral Surg Oral Med Oral Pathol Oral Radiol. 2015;119:196-201.

https://doi.org/10.1016/j.oooo.2014.10.014

16. Shi L, Wan K, Tan M, Yin G, Ge M, Rao X, et al. Risk factors of recurrent aphthous ulceration among university students. Int J Clin Exp Med. 2015;8:6218-223.

17. Safdar NF, Bertone-Johnson E, Cordeiro L, Jafar TH, Cohen NL. Dietary patterns of Pakistani adults and their associations with sociodemographic, anthropometric and life-style factors. J Nutr Sci. 2013;2:e42.

https://doi.org/10.1017/jns.2013.37

18. Yang K, Li Y, Xue Y, Wang L, Liu X, Tu R, et al. Association of the frequency of spicy food intake and the risk of abdominal obesity in rural Chinese adults: a cross-sectional study. BMJ Open. 2019;9:e28736. https://doi.org/10.1136/bmjopen-2018-028736

19. Senusi A, Higgins S, Fortune F. The influence of oral health and psycho-social well-being on clinical outcomes in Behçet's disease. Rheumatol Int. 2018;38:1873-883.

https://doi.org/10.1007/s00296-018-4117-y

20. Herlofson BB, Barkvoll P. Sodium lauryl sulfate and recurrent aphthous ulcers: a preliminary study. Acta Odontologica Scandinavica. 1994;52: 257-59.

https://doi.org/10.3109/00016359409029036

21. Fernandes F, Groisman S, Toledo E, Sampaio F, Verbicario R, Ricardo $\mathrm{H}$, et al. Habits and knowledge about toothpaste of students from Legiao Da Boa Vontade (LBV). J Dent Health Oral Disord Ther. 2015;3:00076. https://doi.org/10.15406/jdhodt.2015.03.00076

22. Abdullah MJ. Prevalence of recurrent aphthous ulceration experience in patients attending Piramird dental speciality in Sulaimani City. J Clin Exp Dent. 2013;5:e89-94.

https://doi.org/10.4317/jced.51042

23. Mohamed S, Janakiram C. Recurrent aphthous ulcers among tobacco users- hospital based study. J Clin Diagn Res. 2014;8:Zc64-lc6. https://doi.org/10.7860/JCDR/2014/10368.5145

24. Mohammed MEA, Brima EI. Cytological changes in oral mucosa induced by smokeless tobacco. Tob Induc Dis. 2019;17:46. Article ID PMID 31516489

https://doi.org/10.18332/tid/109544

25. Sawair FA. Does smoking really protect from recurrent aphthous stomatitis? Ther Clin Risk Manag. 2010;6:573-77.

https://doi.org/10.2147/TCRM.S15145

26. Motamedi MR, Golestannejad Z. Use of pure nicotine for the treatment of aphthous ulcers. Dent Res J (Isfahan). 2015;12:197-8. 